Revista Monografias Ambientais

Santa Maria, v. 14, n. 3, Set-Dez. 2015, p. 76-101

Revista do Centro de Ciências Naturais e Exatas - UFSM

ISSN : 22361308

\title{
Educação Ambiental na escola: do Projeto Político Pedagógico a prática docente
}

Environmental education in schools: the Pedagogical Political Project teaching practice

\author{
Jocieli Aparecida Silva ${ }^{1}$ e Douglas Grzebieluka²
}

${ }^{1}$ Licenciada em Pedagogia, Faculdade Sagrada Família, Ponta Grossa, PR, Brasil

${ }^{2}$ Mestre em Gestão do Território, Departamento de Pedagogia, Faculdade Sagrada Família, Ponta Grossa, PR, Brasil

\section{Resumo}

O presente trabalho propõe-se a fortalecer o processo reflexivo acerca da Educação Ambiental no âmbito escolar e sua abrangência no Projeto Político Pedagógico e na prática docente. A pesquisa descritiva, em uma primeira instância verificou-se por meio do levantamento bibliográfico fazer uma breve contextualização, reconhecendo a importância da Educação Ambiental no processo educativo. Ao reconhecer as dificuldades que permeiam a articulação entre a teoria e a prática, verificou-se a importância da atuação de professores comprometidos com a formação integral do educando de forma que ele possa interagir com competência no meio ambiente. Tendo por base essa prerrogativa, esse trabalho foi vislumbrando a realidade, sobre o desenvolvimento da Educação Ambiental na Educação Formal, fomentando, a preocupação com o desenvolvimento crítico-reflexivo do educando, e com o engajamento dos profissionais da educação na promoção de ações que proporcionem a preservação do meio ambiente, a emancipação humana e a formação de um cidadão consciente de sua ação no mundo. .

Palavras-chave: Educação Ambiental. Educação Formal. Projeto Político Pedagógico.

\begin{abstract}
The present work proposes to strengthen the reflective process about environmental education in schools and its coverage in Politico Pedagogical Project and teaching practice. Through descriptive research, in a first instance we sought through bibliographic make a brief background, recognizing the importance of environmental education in the educational process, compared the current situation. Recognizing the difficulties that pervade the relationship between theory and practice has raised the importance of the role of committed teachers and training integrates the student so that he can interact with competence in the environment. Based on that, this work was being glimpsed reality on the development of environmental education in formal education, encouraging, concern for the development of critical and reflective learners, and engaging education professionals in promoting the conservation actions that provide the environment, human emancipation and the formation of a citizen aware of his action in the world
\end{abstract}

Keywords: Environmental Education. Formal Education. Political Pedagogical Projecto. 
Jocieli Aparecida Silva e Douglas Grzebieluka: Educação Ambiental e Prática Pedagógica

\section{Introdução}

O presente artigo, trata de um instrumento de pesquisa e reflexão sobre o desenvolvimento da Educação Ambiental na Escola. Apresentando a Escola como espaço de Educação Formal que deve corroborar para a formação integral do sujeito, promovendo a efetivação da Educação Ambiental, desde a construção de seus conceitos, concepções e metodologias que constam no Projeto Político Pedagógico, até as ações desenvolvidas pelos professores por meio da práxis educativa.

Desviando-se do padrão geralista, que tende apenas a apontar os aspectos negativos do Projeto Político Pedagógico, das escolas e dos professores, este trabalho objetiva somar esforços, para compreender como a dinâmica da Educação Ambiental tem sido vivenciada nas Escolas públicas e privadas, urbana ou do campo.

Neste sentido, cabe questionar, como tem sido construído e vivenciado o Projeto Político Pedagógico nas escolas, sejam elas públicas, privadas, de meio urbano ou rural; pois todas devem construir suas intenções a partir de fundamentos, concepções e metodologias que levem os educandos, a refletirem sobre as questões ambientais, construído conhecimento e competências fundamentais para transformar a realidade que o cerca.

A temática decorre da emergente problemática ambiental que nos cerca e nos instiga a projetar uma nova ótica, de proporções holísticas, sobre a relação homem com a natureza. Muito se tem escrito e falado sobre as questões ambientais, como um dos maiores problemas da humanidade, porém faz-se necessário uma profunda redefinição de valores e formação de competências essenciais para uma convivência harmônica, e isso apenas será alcançado, como desenvolvimento da Educação Ambiental.

Nesse sentido, o presente trabalho teve por base os princípios defendidos na Pesquisa Descritiva, que permite a "[...] indagação e descoberta da realidade [...], fazendo uma combinação particular entre teoria e dados" para uma melhor compreensão de pontos importantes, no que tange a Educação Ambiental e suas variantes. (MINAYO, 1993, p.23).

No que se refere aos procedimentos metodológicos, a pesquisa foi sustentada inicialmente pela revisão bibliográfica e documental; passando para uma coleta de dados, através da leitura do Projeto Político Pedagógico de quatro Escolas do Município de Carambeí - Paraná. Foram aplicados questionários abertos, destinados aos professores dessas instituições escolares; partindo para a análise dos conteúdos, essencial para o processo de categorização dos elementos identificados durante o percurso da pesquisa. 
A revisão bibliográfica aconteceu a partir do levantamento, seleção e leitura de livros, periódicos, artigos científicos, disponíveis na base on line de dados, documentos legais relacionados com os fundamentos da Educação Ambiental, Educação Formal, do Projeto Político Pedagógico, e da Práxis Educativa entre outras concepções teóricas fundamentais para um estudo mais sólido e contextualizado.

Na pesquisa de campo, fase realizada após o estudo bibliográfico, empreendeu-se tanto a análise dos Projetos Político Pedagógicos, quanto a aplicação dos questionários que foram fundamentais para o delineamento da problemática investigada.

A partir desses processos investigativos, principia-se, em um primeiro momento, a discussão sobre o referencial epistemológico e metodológico, sobre a relevância da Educação Ambiental na Educação Formal, na preocupação de acentuar o conhecimento e a reflexão sobre o papel da Escola, no enfrentamento dos problemas ambientais, que se alastram em escala global.

Segue-se, com a intenção de definir a abrangência da Educação Ambiental no Projeto Político Pedagógico, abordando, qualitativamente, as urgências do desenvolvimento da Educação Ambiental de forma interdisciplinar, integrado de forma holística todas as áreas do conhecimento, em uma relação transversal, contínua e permanente em toda educação básica.

Finalizando, buscou-se realizar uma articulação entre a teoria e a prática, elevando o pensamento crítico sob vieses da práxis educativa, para reconhecimento de como os professores compreendem e abordam a Educação Ambiental frente as peculiaridades do Projeto Político Pedagógico que sustenta os processos de ensino e aprendizagem nas escolas assistidas.

Este trabalho, não ambicionou o esgotamento de todas as hipóteses e perspectivas, em relação as práticas docentes desenvolvidas na Escola, para a efetivação da Educação Ambiental; buscando contribuir e instigar à urgência de se realizarem pesquisas, que possam contribuir auxiliar na compreensão da temática, além de fomentar mudanças de atitudes essenciais, para a solução dos graves problemas ambientais que se vivência na conjuntura atual.

\section{Educação Ambiental no contexto da Educação Formal}

As questões ambientais veem sendo foco de debates e controvérsias em diferentes escalas que atingem nosso planeta. Neste contexto de preocupações mundiais surgem às questões relacionadas à Educação Ambiental; a qual é considerada um tema transversal no currículo escolar, que tem como fundamento a articulação entre teoria e a prática pedagógica; tendo a chance de estar presente em todas as disciplinas por ser um tema interdisciplinar.

Segundo Medina, temos que: 
Educação Ambiental surge como umas das alternativas de transformação no âmbito, de um novo paradigma em construção e de novas formas de pensar interpretar e agir no mundo, possibilitando a visão positiva, instrumental e tecnocrática que se manifesta através da crise global e generalizada deste início do século. A Educação Ambiental visa a construção de relações sociais, econômicas e culturais capazes de respeitar e de incorporar as diferenças (minorias étnicas, populações tradicionais), a perspectiva da mulher e a liberdade para decidir caminhos alternativos de desenvolvimento sustentável respeitando - se os limites dos ecossistemas, substrato de nossa própria possibilidade de sobrevivência como espécie. (MEDINA, 1988, p.51).

Atualmente, a Educação Ambiental pode ser fundamentada numa reelaborarão teórica e pratica dos princípios de três perspectivas teóricas emergentes. Em primeiro lugar, a teoria critica supressora da visão técnica e instrumental; em segundo, a concepção de uma perspectiva complexa da realidade do conhecimento e dos processos de ensino- aprendizagem; e por último, os aportes do construtivismo no sentido amplo do termo, como processo individual e social de construção de conhecimento significativo (MEDINA, 1996).

A Educação Ambiental é, portanto, um processo permanente e contínuo, que não se limita à educação escolar, mas, introduzi-la na escola, inclusive na educação infantil, é uma das estratégias para o seu desenvolvimento (MEYER, 1992).

Educação Ambiental significa educar com a perspectiva da projeção da vida, na vida e por ela. Para tanto se impõe uma escola capaz de se organizar através de diálogos com a realidade, diálogos críticos e propositivos com base na autonomia de ideias e práticas que se entrelaçam permanentemente. (SILVA,2007).

A escola é o ambiente que propicia o desenvolvimento das diversas potencialidades do educando. Sua organização contempla os objetivos previstos nas leis e documentos que regem o sistema educacional brasileiro, nos quais, está previsto a inserção da Educação Ambiental nas práticas docentes. A escola é o primeiro ambiente que traz para perto da criança o contato com a pesquisa, com novas experiências e com o saber sistematizado, mas, não é apenas neste espaço que o ser humano aprende.

Brandão (2007), explica que a educação tem um conceito ampliado e que não existe forma única nem único modelo de educação. Para este autor, a escola também não é o único lugar onde acontece a educação. $\mathrm{O}$ ato de aprender acontece a todo momento, em família, no trânsito, no trabalho, enfim, em diferentes lugares.

Nesse sentido, educação é o conjunto das ações, processos, influências, estruturas que intervêm no desenvolvimento humano de indivíduos e 
grupos na sua relação ativa com o meio natural e social, num determinado contexto de relações entre grupos e classes sociais. (LIBÂNEO, 2005, p.30).

A Lei de Diretrizes e Bases da Educação (LDB) é o documento oficial do Governo Federal que norteia a educação brasileira. A Lei de Diretrizes e Bases 9394/96, define a educação em seu artigo $1^{\circ}$ no seguinte sentido:

Art. $1^{\circ}$-A educação abrange os processos formativos que se desenvolvem na vida familiar, na convivência humana, no trabalho, nas instituições de ensino e pesquisa, nos movimentos sociais e organizações da sociedade civil e nas manifestações culturais. (BRASIL, 1996).

Ainda para Gadotti(2005), a educação é um dos requisitos fundamentais para que os indivíduos tenham acesso ao conjunto de bens e serviços disponíveis na sociedade. Sendo um direito para que possa usufruir de outros direitos constituídos numa sociedade democrática.

Esses conceitos de educação demonstram que ela está diretamente ligada ao ato de aprender, da aquisição, construção e apropriação do conhecimento. E o aprender acontece em muitos lugares e a todo o momento. Segundo Libâneo (2005), por ser uma prática ampla, a educação divide-se em três modalidades: educação formal, informal e não formal.

Ainda segundo Libâneo (2005), educação informal estaria relacionada às ações que acontecem nos vários ambientes em que o ser humano está inserido, que resultam em conhecimentos. Não são ações sistematizadas nem tem intencionalidade.

Para Gadotti:

A educação não-formal é também uma atividade educacional organizada e sistemática, mas levada a efeito fora do sistema formal. Daí também alguns a chamarem impropriamente de "educação informal". São múltiplos os espaços da educação não formal. Além das próprias escolas (onde pode ser oferecida educação não-formal) temos as Organizações NãoGovernamentais (também definidas em oposição ao governamental), as igrejas, os sindicatos, os partidos, a mídia, as associações de bairros[...] (2005, p.02).

A educação formal tem intencionalidade e acontece nas instituições educativas, com certo grau de sistematização. De acordo com Libâneo: “A educação formal compreenderia instâncias de formação, escolares ou não, onde há objetivos explícitos e uma ação intencional institucionalizada, estruturada, sistemática." (2005, p.31).

Polli e Signorini (2012, p.100) consideram a escola como o local propicio para a educação formal que forma para o exercício da cidadania, e que deverá construir projetos que contemplem a Educação 
Ambiental no contexto em que se insere. Entende-se que existem dados que a educação é um fenômeno, uma ação, que pode acontecer em variados locais, entre elas, a escola e a família.

A educação formal trabalha com objetivos claros, seguindo um sistema hierárquico e organizado, que muitas vezes depende burocracia e de muitas especificidades próprias do ambiente escolar, como documentação, ambiente físico, programas e projetos que visem o bom andamento das instituições educacionais para que cumpram com seus objetivos:

A educação formal tem objetivos claros e específicos e é representada principalmente pelas escolas e universidades. Ela depende de uma diretriz educacional centralizada como o currículo, com estruturas hierárquicas e burocráticas, determinadas em nível nacional, com órgãos fiscalizadores dos ministérios da educação. (GADOTTI,2005, p.02).

De acordo com Parâmetros Curriculares Nacionais ( $\left.\mathrm{PCN}^{\prime} \mathrm{s}\right)$, os alunos contam com outras instituições, não escolares, que são a mídia, a família, a igreja, que influenciam sobre o processo da construção dos conhecimentos (PCN's, p.36).

A escola, além de espaço da aquisição do conhecimento, é também o primeiro ambiente socializador depois da família, sendo então estas duas instituições, responsáveis pela formação e desenvolvimento do ser humano.

Segundo Parolin (2012, p.23), nosso primeiro modelo de aprendizagem é o familiar, constituindo também de um ambiente educativo. A família e a escola constituem-se de ambientes de aprendizagem que devem relacionar-se e aproximar-se pelo objetivo final de ambas. É na escola que se propiciam as trocas de experiências, de descobertas, de aproximação com diferentes espaços e culturas:

A escola caracteriza-se como espaço ideal de troca de conhecimento. Diferentes sujeitos, em níveis diferenciados de conhecimento e oriundos de diferentes culturas criam um espectro de possibilidades quase infinitas. (CAMARGO, 1999, p.78).

Como a escola deverá promover a formação plena de indivíduos, bem como a sua emancipação, Educação Ambiental precisa promover também o acesso ao conhecimento que gere uma transformação no pensamento do educando. Segundo Jacobi:

A educação ambiental aponta para propostas pedagógicas centradas na conscientização, mudança de comportamento, desenvolvimento de competências, capacidade de avaliação e participação dos educandos. A relação entre meio ambiente e educação assume um papel cada vez mais desafiador demandando a emergência de novos saberes para apreender processos sociais complexos e riscos ambientais que se intensificam. (2003, p.31). 
A escola constitui-se de um ambiente que propicia as relações sociais e humanas, onde se interage com a natureza e o meio ambiente. (GADOTTI, 2005).

Segundo os Parâmetros Curriculares Nacionais, a Educação Ambiental contribui para a formação de cidadãos plenos, sendo então, parte do conhecimento a ser adquirido e construído em sala de aula. Neste contexto, ao refletir sobre Educação Ambiental na escola, argumenta-se sobre onde e como tratar deste campo do conhecimento:

Como se sabe, a educação constitui uma arena, um espaço social que abriga uma diversidade de práticas de formação de sujeitos. A afirmação desta diversidade é produto da história social do campo educativo, onde concorrem diferentes atores, forças e projetos na disputa pelos sentidos da ação educativa. Por isto, por mais que se argumente que a ideia de educação inclui a educação ambiental, dificilmente se poderá reduzir toda a diversidade dos projetos educativos a uma só ideia geral e abstrata de educação. O que se arrisca apagar sob a égide de uma educação ideal desde sempre ambiental são as reivindicações de inclusão da questão ambiental, enquanto aspiração legítima, sócio-historicamente situada, que sinaliza para o reconhecimento da importância de uma educação ambiental na formação dos sujeitos contemporâneos. (CARVALHO, 2004, p.19).

Por falar da formação de cidadãos contemporâneos, deve-se pensar na escola, na sua função, em seu objetivos, da formação do caráter, da consciência. Formar cidadãos responsáveis, pró ativos, críticos, criativos, que cuidem do espaço em que vivem. Tendo por base o exposto, que a Educação Ambiental, na escola, contribui para a mudança de pensamento, visando ações que assegurem um novo comportamento com relação ao cuidado com o meio ambiente.

A Educação Ambiental se constitui numa forma abrangente de educação, que se propõe atingir todos os cidadãos, através de um processo pedagógico participativo permanente que procura incutir no educando uma consciência crítica sobre as problemáticas ambientais, compreendendo-se a capacidade de captar a gênese, a evolução, e os processos de reversão de tais danos ao meio ambiente. (POLLI, p.08).

No contexto em que vive, o educando interage de alguma maneira com o meio ambiente, seja este natural ou já transformado pelo homem. No entanto, cabe à escola, educá-los para o cuidado com o lixo, demonstrando a importância dos ecossistemas, do desenvolvimento da sustentabilidade, entre outros temas abordados pela Educação Ambiental.

Para Medina (1998), a Educação Ambiental deve mostrar diferentes valores e desenvolver atitudes que busquem posicionamentos diferentes em relação à conservação e utilização dos recursos naturais.

Loureiro(2004) propõe que educar é uma ação que precisa gerar transformação do pensamento. A Educação Ambiental precisa da transformação do pensamento, para que aconteça de maneira efetiva e 
eficaz. Há necessidade de um trato diferente, de posturas diferentes que serão despertadas nos alunos, através de reflexões realizadas em sala de aula.

No ambiente escolar, será possível a interpretação das informações, podendo criar situações de interação entre sala de aula e meio ambiente.

Assim, a escola pode transformar-se no espaço em que o aluno terá condições de analisara natureza em um contexto entrelaçado de práticas sociais, parte componente de uma realidade mais complexa e multifacetada. (JACOBI, 2003, p.10).

A Educação Ambiental deverá garantir que alunos vejam a conservação do meio ambiente, e uso dos recursos naturais como responsabilidade de cada um, buscando a sensibilidade, responsabilidade e a formação para a cidadania.

Jacobi (2003, p. 10) propõe que a Educação Ambiental deve ser vista como um processo de permanente aprendizagem que valoriza as diversas formas de conhecimento e forma cidadãos com consciência local e planetária.

Para além do trabalho com o lixo, e o material reciclado, a Educação Ambiental na escola precisa promover a consciência acerca da importância de determinados valores, e o acesso a informação de como motivar e mobilizar a práticas de responsabilidade.

A Constituição Federal em seu artigo 225 propõe:

Todos têm o direito ao meio ambiente ecologicamente equilibrado, bem de uso comum do povo e essencial à sadia qualidade de vida, impondo-se ao Poder Público e à coletividade o dever de defendê-lo e preservá-lo para as presentes e futuras gerações. (BRASIL,2006).

Desta forma, entende-se a dimensão que a Educação Ambiental vem a ter, se causa nos alunos a reflexão de que o meio ambiente é o espaço comum, e que deverá ser respeitado, bem como seus recursos. Com esse cuidado, as próximas gerações também terão acesso ao meio ambiente equilibrado e sadio.

Todos precisam contribuir para as mudanças no âmbito ambiental. Mas essa ideia tomará maiores proporções se a educação alcançar os seus objetivos, de formar cidadãos críticos, criativos capazes de transformação do meio.

Educação Ambiental e educação para a cidadania estão diretamente ligadas, pois devem dar ao indivíduo a formação ética, baseada e valores que o levem à construção de práticas e ações que apontem alternativas e soluções para os problemas ambientais. 


\section{O Projeto Político Pedagógico e suas relações com a Educação Ambiental}

O Projeto Político Pedagógico de uma escola, define, através de uma construção coletiva o tipo de instituição que a comunidade escolar quer ver funcionar, requer a definição de metas, meios e fins, neste contexto teremos o cidadão que se pretende formar, com uma filosofia própria de ensino.

O trabalho com Educação Ambiental na escola precisa estar também articulado em documentos que embasam as práticas escolares, entre eles, destaca-se o Projeto Político Pedagógico.

O Projeto Político Pedagógico é o documento que embasa todas as ações dentro do ambiente escolar. É também um documento que propõe mudanças; alternativas e soluções que organiza e muitas vezes até manipula o cotidiano de uma escola; reflete o posicionamento da escola frente a sociedade. (POLINARSKI et al., 2009).

Um projeto segundo Ferreira (1975), é um plano, intento, desígnio. Projetar é olhar para frente, buscar o novo. O Projeto Político Pedagógico, portanto, estabelece novos planos, novas atividades. Ele é político por estar ligado a formação de cidadãos e pedagógico por conter a intencionalidade da escola (VEIGA, 2002).

Para Moacir Gadotti:

Todo projeto supõe rupturas com o presente e promessas para o futuro. Projetar significa tentar quebrar um estado confortável para arriscar-se, atravessar um período de instabilidade e buscar uma nova estabilidade em função da promessa que cada projeto contém de estado melhor do que o presente. Um projeto educativo pode ser tomado como promessa frente a determinadas rupturas. As promessa s tornam visíveis os campos de ação possível, comprometendo seus atores e autores. (1994, p. 579).

Por conseguinte, é um documento que prevê as mudanças, e que traz claramente quais objetivos a escola quer alcançar:

Um documento que pressupõe relações de interdependência e reciprocidade entre dois pólos, elaborado coletivamente pelos sujeitos da escola e que aglutina os pensamentos políticos e filosóficos em que a comunidade acredita e os quais deseja praticar; que define os valores humanitários, princípios e comportamentos que a espécie humana concebe como adequados para a convivência humana; que sinaliza os indicadores de uma boa formação e que qualifica as funções sociais e históricas que são de responsabilidade da escola (SILVA, 2003, p. 296).

Cada escola tem autonomia para elaborar o seu Projeto Político Pedagógico, levando em consideração o contexto em que está inserida, a sua realidade social e a necessidades da comunidade.

Para Veiga: 
A principal possibilidade de construção do projeto político-pedagógico passa pela relativa autonomia da escola, de sua capacidade de delinear sua própria identidade. Isto significa resgatar a escola como espaço público, lugar de debate, do diálogo, fundado na reflexão coletiva. Portanto, é preciso entender que o projeto político-pedagógico da escola dará indicações necessárias à organização do trabalho pedagógico, que inclui o trabalho do professor na dinâmica interna da sala de aula[...]. (2002, p. 02).

O Projeto Político Pedagógico também tem a função social, ainda que "camuflada" de demonstrar o caráter autônomo da escola, uma vez que esta, tem autonomia para conceber e executar o seu Projeto Político Pedagógico, além de refletir sobre as suas finalidades sociopolíticas e culturais implícitas em sua realidade. (VEIGA,2002).

Pimenta (1991), afirma que o Projeto Político Pedagógico é a tradução que a Escola faz a partir de suas finalidades, de suas necessidades pessoais e recursos que dispõe. Por esse motivo também, necessita que a comunidade participe da sua elaboração, para que conheça quais são as dificuldades da escola e possa criar e apontar soluções.

A construção do Projeto Político Pedagógico também segue as orientações Lei de Diretrizes e Bases para Educação (LDB), e deve levar em conta os princípios de igualdade, qualidade, gestão democrática e liberdade. Para Saviani (1982, p. 63), o princípio de igualdade diz respeito na possibilidade de democracia, onde a escola seja de todos e para todos $\mathrm{O}$ princípio da igualdade garante que a escola será democrática, e que a escola terá condições de atender aos seus alunos igualmente.

O princípio de qualidade deve garantir o aprendizado, visando à formação e desenvolvimento humano, em todos os sentidos: físico e biológico, psicomotor, moral e cívico. Para Pedro Demo (1994), deve-se garantir a permanência dos alunos que ingressam na escola, sendo que a qualidade implica na formação da consciência crítica e da capacidade de saber agir e mudar.

A gestão democrática acontece quando a escoa consegue trazer para perto dela, os demais envolvidos com o âmbito escolar: a comunidade, alunos, professores, e funcionários. Conferindo a esses a ampla participação na tomada de decisões e conhecimento dos problemas escolares.

No artigo 14ํㅡㄹ da Lei de Diretrizes e Bases da Educação Nacional - Lei 9.394/96, temos que:

Os sistemas de ensino definirão as normas da gestão democrática do ensino público na educação básica, de acordo com suas peculiaridades e conforme os seguintes princípios:

I - participação dos profissionais da educação na elaboração do projeto pedagógico da escola;

II - participação das comunidades escolar e local em conselhos escolares ou equivalentes. (BRASIL, 1996, p. 01). 
Para Gadotti (2005), é mediante a Gestão Democrática que crianças, jovens e adolescentes participam das decisões na escola pública. A construção do Projeto Político Pedagógico visa portanto, a participação democrática da sociedade na vivência escolar. Quanto ao princípio de liberdade, este associa-se a ideia de autonomia. Para Veiga (2002) a liberdade deve ser considerada, também, como liberdade para aprender, ensinar, pesquisar e divulgar a arte e o saber direcionados para uma intencionalidade definida coletivamente.

A gestão democrática da educação formal está associada ao estabelecimento de mecanismos legais e institucionais e à organização de ações que desencadeiem a participação social: na formulação de políticas educacionais; no planejamento; na tomada de decisões; na definição do uso de recursos e necessidades de investimento; na execução das deliberações coletivas; nos momentos de avaliação da escola e da política educacional. Também a democratização do acesso e estratégias que garantam a permanência na escola, tendo como horizonte a universalização do ensino para toda a população. (MEDEIROS, 2003).

Veloso explicita que:

Penso a necessidade do projeto político-pedagógico como uma espécie de carta de intenções e proposições, de compromissos que a escola, como instituição do Estado, faz com a comunidade e com a sociedade como um todo. Nele, ficam definidos e registrados os rumos, desejos, ações, objetivos, metas e finalidades como intencionalidades dos sujeitos que a constituem. Favorece que a comunidade de educandos, pais e responsáveis possam ajudar a construir, acompanhar e também cobrar daquilo que lhe é de direito: educação pública de qualidade e sucesso escolar para todos. (2007, p.82).

Lima (1999), ainda propõe que o princípio democrático, além de garantira participação social e respeitar a decisão da maioria, assegura, na prática, imunidade contra quaisquer tendências autoritárias, elitistas ou excludentes que, por ventura, ameacem a educação e o conjunto das relações sociais.

O Projeto Político Pedagógico, segundo Veiga (2002) é constituído por sete elementos básicos, são eles:
a) as finalidades da escola;
b) a estrutura organizacional;
c) o currículo;
d) o tempo escolar;
e) o processo de decisão;
f) as relações de trabalho e
g) a avaliação. 
Gadotti (2000) propõe o desenvolvimento de uma consciência crítica que envolva a comunidade interna e externa da escola, para que o projeto consiga gerar autonomia, criatividade e responsabilidade.

Sobre as finalidades da escola, devem ficar claras na elaboração do Projeto Político Pedagógico, com propostas que atendam a intencionalidade que a ação educativa tem, que implica em escolhas, valores e compromissos éticos (LIBÂNEO, 2005). Para Gadotti toda educação é, de certa forma, educação formal, no sentido de ser intencional, mas o cenário pode ser diferente: o espaço da escola é marcado pela formalidade, pela regularidade, pela sequencialidade. (2005, p. 02).

Na construção do Projeto Político Pedagógico, a escola deve expor sua organização com relação ao tempo escolar (calendário, horas semanais de aula, dias letivos), para que se organize o currículo de acordo com o tempo hábil para cumpri-lo. (VEIGA, 1998).

A estrutura organizacional compreende as estruturas pedagógicas e administrativas. Segundo Alves:

As estruturas pedagógicas referem-se, fundamentalmente, às interações políticas, às questões de ensino aprendizagem e às de currículo. Nas estruturas pedagógicas incluem-se todos os setores necessários ao desenvolvimento do trabalho pedagógico. [...] As pedagógicas, que, teoricamente, determinam a ação das administrativas, "organizam as funções educativas para que a escola atinja de forma eficiente e eficaz as suas finalidades". (1992, p.21).

O processo de decisão, é aquele que hierarquiza, mas na construção do Projeto Político Pedagógico, deve estimular a participação de todos nos processos de decisão. (VEIGA, 1998). Deve partir de processos eletivos na escolha de seus dirigentes e gestores, a fim da criação da gestão democrática.

Cabe à gestão imprimir eficiência às ações, tanto no que diz respeito ao processo, quanto no que se refere aos resultados, dotando-as de efetividade e eficácia, ou seja, tais ações devem ser adequadas ao problema a ser superado e precisam oferecer bons resultados.

A avaliação no Projeto Político Pedagógico busca conhecer a realidade escolar. Luckesi (2005) sugere que a avaliação traz a dimensão de como a escola tem alcançado seus objetivos. O bom ensino, é o ensino de qualidade que investe no processo de formação, por isso, chega a resultados significativos e satisfatórios. Os resultados não nos chegam, eles são construídos.

A avaliação deve ser diversificada, reconhecendo as diferenças, tecendo saberes, favorecendo a apropriação dos conhecimentos científicos que proporcionem ao educando, a possibilidade participação ativa do processo de tomada de decisão consciente, responsável e comprometida, tendo como ponto de partida a pratica social e a realidade na qual esse sujeito se insere. 
A avaliação implica um encontro com outros, com pessoas, e se concretiza em um projeto de melhoramento que sirva para potencializar os professores através do diálogo e da reflexão de sua prática. Entendida assim, não é uma simples metodologia, mas uma filosofia que define aspectos essenciais que se apoiam em uma teoria do sujeito, da escola, da sociedade, dos valores e do conhecimento". (ENRÍQUEZ; MARTINEZ, 2004, p. 172).

Assim, o Projeto Político Pedagógico deve ser constituído, a partir de referenciais filosóficos, metodológicos e políticos, como uma construção coletiva, processual e participativa, que deve envolver os múltiplos atores do contexto educacional, em um exercício de reflexão que incorpora variáveis internas e externas à prospecção de caminhos que melhor respondam aos anseios, demandas e necessidades da escola; e ser instrumento de luta na medida em que faz valer os princípios democráticos da comunidade escolar a qual pertence.

\subsection{A abrangência da Educação Ambiental no Projeto Político Pedagógico}

Tomando como aporte inicial os referencias apresentados para uma melhor apreciação sobre o Projeto Político Pedagógico, podemos destacar sua valorosa importância para a instrumentalização, das diversas áreas do conhecimento, inerentes ao currículo, atribuindo-lhe, a partir das especificidades a cada uma delas diferentes propostas de ação.

Como eixo norteador da práxis educativa, o Projeto Político Pedagógico é constituído com base no currículo. Por isso deve possibilitar uma reflexão sobre como ele incide no cotidiano escolar, o que será de fundamental importância, para o melhor funcionamento escolar e para propiciar situações que permitam todos os envolvidos no processo educativo a compreender o fazer pedagógico de forma coerente. (ALVES, 1992).

Sendo o viés de orientação para a organização curricular da escola, o Projeto Político Pedagógico precisa ir além de um simples agrupamento de conteúdos, áreas de conhecimento e planos de ensino. Deve buscar a efetivação da intencionalidade da comunidade escolar, em um exercício político de participação e vivência democrática, que por meio de alternativas viáveis, de fins emancipatórios, pretende dar qualidade à intervenção do ser humano no contexto em que vive.

Nessa perspectiva, a Educação Ambiental precisa estar incorporada ao Projeto Político Pedagógico, pois, é fundamental para o despertar da consciência do sujeito, frente à problemática socioambiental que nos cerca. A Educação Ambiental deve estar presente de forma abrangente no Projeto Político Pedagógico, permeando todos os níveis de ensino em caráter formal e não formal (BRASIL, 1999).

Por estar voltada para a construção de competências essenciais à conservação do meio ambiente, à qualidade de vida e a sustentabilidade, na maioria das vezes, suscita-se a necessidade da Educação 
Ambiental aparecer no Projeto Político Pedagógico por meio de uma proposta de transversalidade. Essa proposta pode ser trabalhada nas diferentes áreas do conhecimento de forma interdisciplinar, integrando conteúdos referentes aos aspectos físicos, históricos, sociais, econômicos e políticos da Educação Ambiental, que compõe a temática.

Não basta apenas a Educação Ambiental estar inserida nos documentos oficiais da escola, ela deve estar vinculada às causas, aos desafios, aos sonhos, à história e à cultura dos povos que vivem no meio em que se estuda. Precisa-se encontrar um lugar apropriado para a Educação Ambiental dentro do projeto educativo das escolas, tendo claro qual o seu papel na reconstrução do sistema de relações entre as pessoas, a sociedade e o ambiente natural (SAUVÉ, 1999).

Como prática transformadora na construção da cidadania planetária e da sustentabilidade; o desenvolvimento da Educação Ambiental deve ser vivenciado por meio de experiências significativas e interdisciplinares, que garantam aos sujeitos a possibilidade de adquirir conhecimentos e competências essenciais para torna-los aptos a resolver problemas ambientais que os atingem tanto no âmbito individual quanto coletivo.

Nessa dinâmica, a Educação Ambiental, precisa estar incorporada ao Projeto Político Pedagógico, de modo a fomentar práticas reflexivas sobre a problemática acerca da conjuntura atual que se estabelece devido à utilização desordenada do meio ambiente “[...] que configura o esgotamento de um estilo de desenvolvimento ecologicamente predador, socialmente perverso, politicamente injusto, culturalmente alienado e eticamente repulsivo". (GUIMARÃES, 2001, p. 51).

Nessa perspectiva, o propósito da Educação Ambiental no Projeto Político Pedagógico, deve emergir do imperativo de "civilizar e solidarizar a Terra, transformar a espécie humana em verdadeira humanidade, torna-se o objeto fundamental e global de toda educação que aspira não apenas ao progresso, mas à sobrevivência da humanidade" (MORIN, 2000, p. 78).

A transversalidade será um meio para a abordagem da Educação Ambiental na escola, buscando legitimar esse processo pluridimensional, que além de relacionar e articular os diferentes conteúdos às diversas áreas do conhecimento contribui, potencialmente, para a formação integral do sujeito, na medida em que os resultados dos estudos fomentem a reflexão, a criticidade e a tomada de consciência.

Conforme Medina (1996, p.20) tem-se que:

A Educação Ambiental, como tema transversal, possibilita a opção por diferentes situações desejadas, balizadas por valores como responsabilidade, cooperação, solidariedade e respeito pela vida, integrando os conteúdos disciplinares e os temas transversais. Coloca-se dentro de uma concepção de construção interdisciplinar do conhecimento, visa a consolidação da cidadania a partir de conteúdos vinculados ao cotidiano e aos interesses da maioria da população. 
Tudo isso pode ser confirmado no art. 1ำ da (LEI 9.795/99, que apontada a Educação Ambiental como:

[...] processos por meio dos quais o indivíduo e a coletividade constroem valores sociais, conhecimentos, habilidades, atitudes e competências voltadas para a conservação do meio ambiente, bem de uso comum do povo, essencial à sadia qualidade de vida e sua sustentabilidade. (BRASIL,1999, p.01).

Nesse sentido, a efetivação da Educação Ambiental reside no fato do Projeto Político Pedagógico possibilitar dentro de suas concepções e intencionalidade, a articulação dessa temática aos diferentes conteúdos das diversas áreas do conhecimento, o que contribuirá, potencialmente, para a formação integral do sujeito, além disso, conforme Morin:

[...] na Educação Ambiental crítica, o conhecimento, para ser pertinente não deriva de saberes desunidos e compartimentalizados, mas da apreensão da realidade a partir de algumas categorias conceituais indissociáveis aos procedimentos pedagógicos (2002, p. 45).

Deste modo, essa integração da Educação Ambiental a outras áreas do conhecimento produz situações que tornam a aprendizagem mais dinâmica e mais eficaz, provocando a reflexão e o questionamento, que podem alcançar perspectivas de transformação em diferentes esferas, como as relacionadas aos problemas sociais, econômicos, políticos, entre outros.

Na busca da consolidação de novas estratégias de ensino e aprendizagem que sejam capazes de promover as transformações da realidade, pretendidas por um Projeto Político Pedagógico que ambicione em suas intenções a qualidade na educação e a formação integral do indivíduo, faz-se necessário uma metodologia que incorpore elementos que extrapolem a educação tradicional.

Uma forma atraente de trabalhar essa temática é por meio do desenvolvimento de Projetos. Essa metodologia deve compor os pressupostos do Projeto Político Pedagógico, dando nova forma e conteúdo ao processo de ensino, além de uma nova dinâmica a aprendizagem, o que favorecerá a formação de hábitos e atitudes, conceitos e competências que podem ser utilizados na resolução de situações alheias à vida escolar (HERNÁNDEZ; VENTURA, 1998).

Ao conceber o desenvolvimento da Educação Ambiental através da prática de Projetos, a escola, por meio de seu Projeto Político Pedagógico, pode criar uma forma de contribuir decisivamente, no processo de compreensão e transformação da problemática que gira entorno dessa temática, pelo apoio teórico e instrumental, que compõe essa metodologia de trabalho.

Para que haja uma solida construção de pressupostos no Projeto Político Pedagógico, é preciso que todos participem plenamente do processo de tomada de decisões, pois a funcionalidade e as intenções, 
enfatizadas nesse instrumento, serão a bússola me norteará a difusão e efetivação da Educação Ambiental em todo o currículo escolar.

Assim, a partir do reconhecimento de que é necessário compreender as questões ambientais de forma transversal e interdisciplinar, desenvolvendo-a por meio de práticas inovadoras e criativas. A abrangência da Educação Ambiental irá ampliar as possibilidades e a aplicabilidade do Projeto Político Pedagógico, estimulando o comprometimento com a justiça social, qualidade de vida, equilíbrio ambiental, abrindo possibilidades para uma ação verdadeiramente transformadora.

\section{Articulações entre teoria e prática: do Projeto Político Pedagógico a Prática Docente em Educação}

\section{Ambiental}

Frente às prerrogativas da Educação Ambiental abordadas no decorrer deste trabalho, faz-se necessário compreender as ações e práticas que estão sendo desenvolvidas nas escolas; neste contexto é de suma importância uma análise no Projeto Político Pedagógico nas questões que se referem às práticas de Educação Ambiental e como estas ações estão sendo desenvolvidas juntamente com os alunos.

Para o desenvolvimento de um processo investigativo mais contextualizado, foram feitas análises do Projeto Político Pedagógico de quatro escolas do Município de Carambeí. Nessas análises, buscou-se verificar as propostas referentes à Educação Ambiental. Foram aplicados questionários, junto aos professores dessas instituições escolares, a fim de obter, a partir do reconhecimento de suas práticas, a concepção dos professores sobre a promoção da Educação Ambiental em suas escolas.

Não há como compreender as propostas pedagógicas de uma escola, longe das concepções estabelecidas em seu Projeto Político Pedagógico. Através de documentos como o Projeto Político Pedagógico é possível ter acesso a realidade escolar de forma complexa e contextualizada (BOGDAN; BIKLEN, 1994).

O Projeto Político Pedagógico serve de elemento para reflexão, bem como para comunicar os problemas, metas, ações, princípios e valores, coletivamente discutidos e assumidos pela comunidade escolar, no direcionamento do processo de ensino e aprendizagem.

O Projeto Político Pedagógico é um projeto, "termo que vem do latim: projectu, do verbo projicere, que significa lançar para diante" (VEIGA 2004, p. 11), ou seja é um instrumento de definição de caminhos e rumos que se pretende tomar para possibilitar um trabalho escolar sistemático e organizado.

Nessa perspectiva, a importância da análise do Projeto Político Pedagógico, das escolas selecionadas, tornou-se fundamental para os estudos e o debate acerca da pratica docente em 
Educação Ambiental, pois, pode-se refletir sobre o viés de duas dimensões, a política é a pedagógica, que "possibilita a efetivação da intencionalidade da escola, que é a formação do cidadão participativo, responsável, compromissado, crítico e criativo" (VEIGA,1998, p. 12, apud BAFFI, 2001, p. 03).

As escolas escolhidas no Município de Carambeí, Paraná, foram três instituições públicas e uma privada; dentre as públicas, uma delas voltada para a Educação do Campoํ. Para nomear essas escolas utilizaremos a letra E, seguida de um número conforme tabela abaixo (TABELA 01):

TABELA 01: IDENTIFICAÇÃO DAS ESCOLAS

\begin{tabular}{|l|l|}
\hline $\begin{array}{l}\text { ESCOLAS } \\
\text { PESQUISADAS/MANTENEDORA/LOCALIZAÇÃO }\end{array}$ & $\begin{array}{l}\text { IDENTIFICAÇÃO DAS ESCOLAS } \\
\text { PELA PESQUISADORA }\end{array}$ \\
\hline Escola Elo Sagrado/Particular/Urbana & Escola E1 \\
\hline Colégio Eurico Batista Rosas/Estadual/Urbana & Escola E2 \\
\hline Colégio Julia Wanderlei/Estadual/Urbana & Escola E3 \\
\hline Colégio Darlene de J. P. Moreira/Estadual/Campo & Escola E4 \\
\hline
\end{tabular}

ORG: SILVA, JOCIELI APARECIDA, 2014.

Acompanhando a análise do Projeto Político Pedagógico de cada escola serão apresentados os apontamentos dos professores sobre o desenvolvimento da Educação Ambiental, nessas instituições.

Em relação as análise do Projeto Político Pedagógico das escolas selecionadas, apenas a E3 traz uma breve concepção sobre a Educação Ambiental. Verifica-se neste Projeto Político Pedagógico que ele possui fundamentos epistemológicos e metodológicos que permitem o desenvolvimento de ações abrangentes às problemáticas atuais da sociedade, como a Educação Ambiental. Destaca-se o compromisso com a formação integral do educando, com o desenvolvimento de competências fundamentais para uma inserção qualitativa na sociedade, abrem possibilidades de desenvolvimento da Educação Ambiental, pois essas referências gerais são básicas para o processo educativo de qualquer área do conhecimento, seja como ponto de partida quanto de chegada.

${ }^{1}$ EDUCAÇÃO DO CAMPO: Objetiva-se que o estudo tenha a investigação como ponto de partida para a seleção e desenvolvimento dos conteúdos escolares, de forma que valorize singularidades regionais e localize características nacionais, tanto em termos das identidades sociais e políticas dos povos do campo quanto a valorização da cultura de diferentes lugares do país. "Os sujeitos do campo têm direito a uma educação pensada, desde o seu lugar e com a sua participação, vinculada à sua cultura e as necessidades humanas e sociais." (PARANÁ, DIRETRIZES CURRICULARES ESTADUAIS - EDUCAÇÃO DO CAMPO, 2006, p. 09). 
Na escola E1, que é privada, evidencia-se as possibilidades de desenvolvimento da Educação Ambiental, ao ser considerado a perspectiva de "[...] integrar ao trabalho pedagógico a prática interdisciplinar e contextualizadora;" uma das metas estabelecidas para trabalho pedagógico que ambiciona desenvolver. (PROJETO POLÍTICO PEDAGÓGICO, ESCOLA E1, p. 14). Na concepção de currículo, presente no Projeto Político Pedagógico da escola E1, encontram-se alguns traços de que a escola trabalha a Educação Ambiental.

O currículo escolar deve, portanto, possibilitar ao aluno estabelecer relações com o meio ambiente, percebendo-se parte dele; entender as relações de trabalho estabelecidas entre os homens, bem como se entender como integrante de uma cultura, valorizando suas formas próprias de pensar, agir e de se expressar, sem desconsiderar o intercâmbio entre as diferentes culturas. E, finalmente, é preciso que a escola ofereça ao aluno oportunidades para ele se apropriar das linguagens do seu tempo. (PROJETO POLÍTICO PEDAGÓGICO, ESCOLA E1, p. 34).

Além disso, há menção aos valores éticos, sociais, políticos e morais que são indispensáveis ao desenvolvimento do cidadão em sua plenitude, que podem subsidiar o desenvolvimento da Educação Ambiental, tais como: "fortalecimento dos laços de solidariedade e de tolerância recíproca; formação de valores; aprimoramento como pessoa humana; formação ética; exercício da cidadania." (PROJETO POLÍTICO PEDAGÓGICO, ESCOLA E1, p. 35).

Mesmo encontrando pequenas evidências, a escola E1, não faz menção ao desenvolvimento de um Projeto especifico de Educação Ambiental, há em seu Projeto Político Pedagógico, a proposta desenvolvimento de "subprojetos", contudo é dada ao professor, a liberdade de escolher temas e trabalha-lo dentro dos conteúdos estabelecidos para as diferentes áreas do conhecimento. (PROJETO POLÍTICO PEDAGÓGICO, ESCOLA E1, P. 58).

Essa perspectiva de liberdade de escolha é confirmada ao analisarmos as respostas dadas pelos professores, ao questionário aplicado para corroborar com a pesquisa sobre a prática docente em Educação Ambiental, desenvolvida na escola E1. Percebe-se pelas respostas que são desenvolvidas ações pontuais, principalmente, dentro da organização dos conteúdos e das rotinas escolares, que remetem ao cuidado com a natureza e a separação e reciclagem do lixo.

Embora fomente a intensão de preservar o meio ambiente, ações pontuais, como separar o lixo na hora do lanche e explorar o lixo reciclável, transformando-os em novos utensílios, tem um fim em si mesmo, e para uma Educação Ambiental sólida e transformadora, há que se considerar um aspecto mais amplo, de formação para vida.

Já na análise do Projeto Político Pedagógico da escola E2, instituição pública de área urbana encontrou-se um currículo orientado de forma disciplinar, constituído pelo ensino e aprendizagem de conhecimentos sistematizados historicamente. Neste caso, a opção pelo currículo escolar por 
disciplinas, foi escolhida devido à crença estabelecida pelo coletivo escolar que construiu esse Projeto Político Pedagógico, que essa divisão garante:

[...] a especificidade do conhecimento a partir de cada disciplina com suas múltiplas relações históricas, sociais, culturais e políticas. buscando-se prioritariamente o desenvolvimento das capacidades de pesquisar, buscar informações, analisá-las e selecioná-las, a capacidade de aprender, de criar, de formular ao invés do simples exercício de memorização, a capacidade de comunicar-se adequadamente, a autonomia intelectual, para resolver problemas práticos utilizando os conhecimentos científicos. (PROJETO POLÍTICO PEDAGÓGICO, ESCOLA E2, P. 24).

No Projeto Político Pedagógico da escola E2, não contempla uma referência direta de um trabalho interdisciplinar que abranja a Educação Ambiental. Há uma ressalva, destacando que:

[...] as diferentes temáticas selecionadas aos desafios educacionais contemporâneos, tais como cidadania, ética, educação sexual, preservação do meio ambiente, cultura afrodescendente, indígenas, trabalho infantil e outros temas necessários serão trabalhados em todas as oportunidades, sendo de responsabilidade de cada professor buscar despertar o processo de reflexão no aluno acerca dos problemas inerentes ao meio que se encontra inserido. (PROJETO POLÍTICO PEDAGÓGICO, ESCOLA E2, P.24).

O Projeto Político Pedagógico da escola E2traz, dentro dos planos e projetos de enriquecimento curricular, uma ação de combate ao desperdício de energia elétrica, que tem como medida preventiva a fiscalização do uso, no intuito de reeducação da comunidade escolar para a conservação desse recurso hídrico.

Percebe-se que a Educação Ambiental, no Projeto Político Pedagógico da escola E2, aparece apenas como uma sugestão temática, ou em projetos extracurriculares, sua concepção não integra os fundamentos teóricos e metodológicos deste documento. Isso também é evidenciado na resposta dos professores ao questionário aplicado durante essa pesquisa, nas quais apontam a inexistência da Educação Ambiental neste espaço escolar. Em resumo as questões ambientais aparecem desvinculadas do Projeto Político Pedagógico, tendo apenas sutil presença, em interações dialógicas, como lembrete aos educandos da necessidade de preservação da natureza.

Procuro sempre conversar com os alunos para terem ações de conservação do meio ambiente dentro e fora da escola. [...] Devemos em primeiro lugar ser o exemplo para as crianças, e sempre conversar sobre onde se deve jogar o lixo e como fazer a seleção de lixo e também [...] sobre o desperdício da água. (PROFESSOR A, ESCOLA E2). 
Neste caso a Educação Ambiental aparece apenas como atividade complementar e não como área do conhecimento, que contextualizada a uma problemática socioeducativa, deve ser trabalhada de forma holística, a fim de construir competências fundamentais para uma real mudança de atitude, que contribuam para a preservação do meio ambiente como um todo.

Na sequência, analisou-se a escola E3, outra escola pública de área urbana. Em seu Projeto Político Pedagógico, encontram-se contemplados fundamentos teóricos metodológicos abrangentes que se pretendem alcançar, quando vivenciados na prática, a otimização do processo educativo, a qualidade de vida, o exercício da cidadania e a garantia de direitos, como os previstos na Lei 9795/99, que institui a Política Nacional de Educação Ambiental, por meio da Agenda 21. (BRASIL, 1999).

Assim, para que sejam cumpridos os dispositivos legais estabelecidos no âmbito Federal e Estadual, o Projeto Político Pedagógico da escola E3, busca integrar em suas concepções teóricas e metodológicas a Educação Ambiental, definida como tema transversal que deve ser trabalhado de forma interdisciplinar "[...] em todas as áreas do conhecimento com o mesmo grau de responsabilidade, em todos os níveis e modalidades de ensino". (PROJETO POLÍTICO PEDAGÓGICO, ESCOLA E3, p. 20).

Além disso, este Projeto Político Pedagógico orienta e contempla a Educação Ambiental sob uma ótica holística, considerando a pertinência de problematizar as questões ambientais, em todas as áreas do conhecimento, para suscitar a construção de um processo continuo e permanente de desenvolvimento de competências, que garantam a participação qualitativa dos educandos, em ações que busquem a preservação e a resolução dos problemas ambientais.

Ao longo do Projeto Político Pedagógico são fomentadas diferentes formas de desenvolvimento da Educação Ambiental, como o Projeto, nomeado pela E3 como “Agenda 21", que pretende:

- Desenvolver ações para a restauração da vegetação ciliar na Bacia do Rio São João.

- Obter o diagnóstico ambiental da Bacia do Manancial São João, definindo os problemas a partir das discrepâncias encontradas na comparação entre a situação real e a desejada.

- Conscientizar os proprietários da preservação das matas ciliares.

- Disseminar conceitos de educação ambiental entre os estudantes. (PROJETO POLÍTICO PEDAGÓGICO, ESCOLA E3, p.68).

O Projeto "Agenda 21" tem por objetivo à restauração da vegetação ciliar, a proteção do manancial e educação sócio ambiental dos alunos e da comunidade moradora, nos arredores da bacia do rio São João, situada no território dos Municípios de Castro e Carambeí. No intuito de obter sucesso no alcance desses objetivos a escola E3 conta com: 
[...] a participação de toda a comunidade escolar, com orçamento em contrapartida da Sanepar (recursos do Fundo azul) $\mathrm{R} \$ 29.999,99$ (vinte e nove mil novecentos e noventa e nove reais e noventa e nove centavos), contrapartida interna da DMA $\mathrm{R} \$ 1.400,00$ (mil e quatrocentos reais), além das parcerias com a Prefeitura Municipal de Carambeí, via Secretaria Municipal do Meio Ambiente e Departamento Municipal de Extensão Rural; EMATER (Empresa Paranaense de Assistência Técnica e Extensão Rural) e o CEPET (Centro de Educação Profissional de Ensino Técnico - Curso Técnico em Meio Ambiente).(PROJETO POLíTICO PEDAGÓGICO, ESCOLA E3, p.70- 71).

Através dessa ação conjunta, espera-se melhorar a qualidade das águas desses mananciais, que sofrem constantemente impactos ambientais causados pela degradação da mata ciliar. Devido a especificidades do trabalho desenvolvido por esses parceiros é possível fornecer suportes técnicos, indispensáveis para nortear as ações do projeto, especialmente na elaboração de um diagnóstico especializado mais preciso da situação ambiental relacionando meio físico, biológico, social e econômico do local.

Além disso, como fontes de recursos para estruturá-lo, o suporte financeiro, contribuí para a execução do respectivo projeto e garante a continuidade das ações de recuperação e de conservação, o que garante maior efetividade à proteção da bacia do Rio São João.

Por prever em sua proposta, ações voltadas para a pesquisa, reflexão e participação dos educandos, em uma preponderante e urgente recuperação e proteção da mata ciliar desse manancial, pode-se considerar no Projeto Político Pedagógico da escola E3, o desenvolvimento de uma Educação Ambiental, por meio da mobilização comunitária e solidária, frente a necessidade de agir contra esses problemas ambientais, na perspectivas de intervir na situação e transformar a realidade.

Embora, o Projeto Político Pedagógico apresente perspectivas para o desenvolvimento qualitativo e ideal da Educação Ambiental, não foi possível confirmar como os professores se posicionam frente a essas premissas, pois não houve colaboração desses profissionais para a aplicação do questionário de investigação da prática docente.

Nessa abordagem, segue a análise do Projeto Político Pedagógico da escola E4, instituição pública da área Rural. No início da apresentação do Projeto Político Pedagógico, a escola E4, apresenta seu "nicho de trabalho", como um espaço que emerge diretamente em meio à natureza. Frente a isso, aspira em sua missão:

Assegurar ensino de qualidade, contribuir para a melhoria das condições educacionais, formar cidadãos de bem, conscientes de seus direitos e deveres, que saibam interagir no meio em que vive, preservando a natureza e respeitando o ambiente [...]. (PROJETO POLÍTICO PEDAGÓGICO, ESCOLA E4, p. 21-22). 
No entanto, seguindo na análise percebe-se que aparecem apenas indícios que há a promoção de atividades que visam sensibilizar os educandos para a Educação Ambiental, cujas ações cotidianas, como: a "realização de peças teatrais, danças, filmes, dinâmicas de grupos, passeios, seminários, exposições e feiras $[. . .]^{\prime \prime}$, podem ser voltadas para abordagem das questões ambientais. (PROJETO POLÍTICO PEDAGÓGICO, ESCOLA E4, p. 38).

Essa ideia de desenvolvimento da Educação Ambiental, por meio de atividades aleatórias “[...] trabalhada de forma simples [...]", conforme resposta dada pelo Professor B da escola E2, não traduz a complexidade da Educação Ambiental que exige a integração de diversos componentes educacionais, capazes de ajudar os educandos a construírem uma consciência global sobre das questões relativas ao ambiente e assumirem posições afinadas à sua proteção e melhoria.

Para a Educação do Campo isso é ainda mais pertinente, o contato direto do homem coma natureza, pressupõe o desenvolvimento de uma Educação Ambiental, que promova:

[...] um processo de reflexão sobre modelos de desenvolvimento rural, para que sejam responsáveis, economicamente viáveis e socialmente aceitáveis, que colaborem para a redução da pobreza, para a conservação dos recursos naturais e da biodiversidade, para a resolução dos problemas ambientais, fortalecendo as comunidades que vivem no campo, não dissociando a complexidade da sociedade e da natureza. (ZAKRZEVSKI, 2004, p. 85).

Portanto, o trabalho com a Educação Ambiental, em escolas do campo como a E4, deve transpor a visão simplista e descontextualizada, partindo para o desenvolvimento de ações significativas, na qual seja possível, para o educando, estabelecer vínculos de aprendizagem com o espaço que o cerca, como vieses para o empoderamento comunitário, para a preservação da natureza e combate a degradação do meio ambiente.

Nas análises realizadas no Projeto Político Pedagógico dessas quatro escolas, percebe-se que o desenvolvimento da Educação Ambiental, ainda engatinha rumo ao que se espera alcançar. Frente a conjuntura atual e o que está previsto nas bases legais, o que se vê são atividades que podem ter relações com a temática ambiental, porém não se configuram como práticas de formação integral.

Em um processo de sinergia, a Educação Ambiental ideal deve emergir da abordagem coletiva, participativa e solidária, que correlacione os aspectos históricos, culturais, sociais, econômicos e políticos à problemática ambiental que se configura na atualidade.

Neste sentido, cabe questionar, como tem sido construído e vivenciado o Projeto Político Pedagógico nas escolas, sejam elas públicas, privadas, de meio urbano ou rural; pois todas devem construir suas intenções a partir de fundamentos, concepções e metodologias que levem os educandos, a refletirem sobre as questões ambientais, construído conhecimento e competências fundamentais para transformar a realidade que o cerca. 


\section{Conclusões}

Frente às análises realizadas ao longo da construção desse trabalho, concluiu-se que a Educação Ambiental na Escola deve potencializar o desenvolvimento de práticas reflexivas, que realmente contribuam para uma melhor investigação das possíveis causas e efeitos da problemática ambiental que assola a sociedade nos dias atuais.

Nessa pesquisa, percebeu-se que as realidades escolares assistidas, encontram-se bem distante do que se espera, tanto na definição de concepções que devem estar contidas no Projeto Político Pedagógico, quanto nas vivências desenvolvidas pelos professores para o desenvolvimento da Educação Ambiental.

Ao analisar o Projeto Político Pedagógico, dessas escolas e verificar como os professores pensam e realizam a Educação Ambiental nesses espaços de Educação Formal, foi possível perceber que ainda existe um longo caminho a ser percorrido, em direção a uma Educação Ambiental capaz de contribuir para a construção de uma nova ética e posturas que realmente promovam a transformação da realidade.

Focada apenas em ideias gerais, que não permitem a construção das competências necessárias, para fomentar a reflexão e sensibilização do educando, a Educação Ambiental presente no universo de pesquisa desse trabalho, se mostrou pouco presente no Projeto Político Pedagógico das escolas analisadas; no movimento dialético existente entre teoria e prática e nas vozes dos profissionais, não atendendo de maneira satisfatória as demandas que emergem das questões ambientais.

Mesmo assim, percebe-se que existe vontade, por parte significativa dos docentes em desenvolverem a Educação Ambiental em suas práticas, porém, a escola necessita disponibilizar bases sólidas em diversos aspectos, como por exemplo, em seus Projeto Político Pedagógico, apresentando quais ações devem ser desenvolvidas nas práticas de Educação Ambiental. Os trabalhos de Educação Ambiental realizados são, quase sempre, fruto de esforços pessoais e/ou coletivos de profissionais que demonstram preocupação com as questões ambientais.

Como um importante referencial, o Projeto Político Pedagógico é um documento de fundamental importância para a construção de um trabalho sistematizado dentro da escola. Sua construção, entretanto, deve ocorrer a partir do levantamento das necessidades da comunidade escolar na qual está inserido.

Ao reconhecer as demandas socioambientais do seu entorno, o Projeto Político Pedagógico, a partir do estabelecimento de princípios, concepções e diretrizes que reflitam a necessidade da 
comunidade escolar, quando bem elaborado, pode promover mudanças em diversos aspectos que são essenciais para a sociedade.

No caso específico da Educação Ambiental, isso tem se constituído um desafio ainda maior, pois como práxis social deve ser baseado em princípios e concepção que considerem o meio ambiente em sua totalidade, reconhecendo sua interdependência com fatores sociais, políticos, econômicos, demográficos, biológicos, culturais e institucionais e sua finalidade de formação integral dos sujeitos, para que sejam capaz de agir com responsabilidade em seu espaço de convivência.

Nessa perspectiva, a tomada de consciência é fundamental para garantir uma diminuição das degradações do meio ambiente, causadas pelas ações humanas. Ao fazer parte desse grande movimento em defesa da vida, a partir de processos dinâmicos e interdisciplinares de Educação Ambiental, o educando torna-se cidadão participante, crítico, responsável e comprometido na redefinição de valores e práticas que realmente surtam efeitos de mudança na problemática socioambiental que viola ou nega seus direitos.

Considera-se que a Educação Ambiental, sendo um processo de aprendizagem permanente, precisa ser repensada pelos profissionais da educação e reelaborada no Projeto Político Pedagógico, não só para que sejam efetivadas as bases legais, mas, também para que o educando possa desenvolver as competências necessárias para a justiça social, qualidade de vida, equilíbrio ambiental, abrindo possibilidades para uma ação em busca de alternativas e soluções para preservação do meio ambiente e continuidade da vida humana.

\section{REFERÊNCIAS}

ALVES, J. M. Organização, gestão e projecto das escolas. Porto, Edições Asa, 1992.

BOGDAN, R. \& BIKLEN, S. K. Investigação qualitativa em educação: uma introdução à teoria e aos métodos. Porto, Portugal: Editora Porto, 1994.

BRANDÃO, C. R. O que é Educação. São Paulo:Brasiliense,2007.

BRASIL. Constituição (1988). Constituição da República Federativa do Brasil. Brasília, DF: Senado Federal: Centro Gráfico, 198.

BRASIL. Lei de Diretrizes e Bases da Educação Nacional. Lei no 9394, de 20 de dezembro de 1996.

BRASIL. Ministério da Educação. Secretaria de Educação Básica. Parâmetros nacionais de qualidade para a educação infantil. Ministério da Educação. Secretaria de Educação Básica: Brasília (DF), 2006 v.l; il.

CAMARGO, J. S. Interação Professor - Aluno: A Escola como Espaço Interativo. In: MARTINS J.B.(org) Na Perspectiva de Vigotsky. São Paulo: Quebra Nozes/Londrina:1999. 
CARVALHO, I. C. M. Educação Ambiental: a formação do sujeito ecológico. São Paulo: Cortez, 2004.

DEMO, P. Educação e Qualidade. Campinas: Papirus,1994.

GADOTTI, M. Pressupostos do projeto pedagógico. In: MEC, Anais da Conferência Nacional de Educação para Todos. Brasília, 28/8 a 2/9/94.

GUIMARÃES, M. Educação ambiental: no consenso um embate? 4a ed. Campinas: Papirus, 2001.

A QUESTÃO DA EDUCAÇÃO FORMAL/NÃO-FORMAL.In: INSTITUT INTERNATIONAL DES DROITS DE L'ENFANT (IDE) Droit à l'éducation: solution à tous les problèmes ou problème sans solution?SUISSE, 18 a 22 de outubro de 2005

Perspectivas atuais da educação. Porto Alegre: Artes Médicas, 2000

HERNÁNDEZ, F.; VENTURA, M. A organização do currículo por projetos de trabalho: o conhecimento é um caleidoscópio. Porto Alegre: Artes Médicas, 1998.

JACOBI,P. Educação Ambiental, Cidadania e Sustentabilidade. In: Cadernos de Pesquisa. USP, São Paulo: ${ }^{\circ} 118$. p. 189-205,2003.

LIBÂNEO,J.C. Pedagogia e Pedagogos , para quê? São Paulo: Cortez, 2005.

LIMA, Gustavo Ferreira da Costa. "Questão ambiental e educação: contribuições para o debate". Ambiente \& Sociedade, NEPAM/UNICAMP, Campinas, ano II, nº 5, 135-153, 1999.

LOUREIRO, C.F.B. Trajetória e Fundamentos da Educação Ambiental. São Paulo: Cortez,2004.

LUCKESI,C.C. Avaliação da Aprendizagem...mais uma vez. In: Artigo publicado na Revista ABC EDUCATIO no 46, junho de 2005, páginas 28 e 29. 2005.

MEDINA, N. M.; SANTOS, E. da C. Educação ambiental: uma metodologia participativa de formação. Petrópolis: Editora Vozes, 2000.

MEYER, M. A. A. Ecologia faz parte do espaço cotidiano. AMAE EDUCANDO. Belo Horizonte, n.225, p.13-20, 1992.

MINAYO, M. C. S. Ciência, técnica e arte: o desafio da pesquisa social. In: MINAYO, M. C. S. (Org.). A pesquisa social: teoria, método e criatividade. 9 ed. Rio de Janeiro: Petrópolis, 1998. p. 9-29.

MORIN, E. Ciência com consciência. Rio de Janeiro: Bertrand Brasil, 2002.

POLLI, A. e SIGNORINI, T. A inserção da Educação Ambiental na prática pedagógica. In:Revista Ambiente \& Educação .V 17, № 2,RIO GRANDE :2012

PAROLIN, Isabel. Limites-respeito e superação. Curitiba: Expoente, 2012.

SAUVÉ, L. Educação Ambiental: possibilidades e limitações. In: Educação e Pesquisa. vol.31, no.2, São Paulo, May/Aug. 2005. * Traduzido do original L'éducation relative à l'environnement: possibilités et contraintes, Connexion (Revista de Educação Científica, Tecnológica e Ambiental da UNESCO), v. XXVII, n. 1-2, p. 1-4, 2002. Tradução de Lólio Lourenço de Oliveira. 
SILVA,M.L. A Escola Bosque e suas Estruturas Educadoras- uma casa de educação ambiental. In Vamos cuidar do Brasil : conceitos e práticas em educação ambiental na escola /Coordenação: Soraia Silva de Mello, Rachel Trajber]. - Brasília:Ministério da Educação, Coordenação Geral de Educação Ambiental: Ministério do Meio Ambiente,Departamento de Educação Ambiental : UNESCO, 2007.

VEIGA, I. P. A. Projeto Político-pedagógico da escola: uma construção possível. Campinas, São Paulo. Papirus 1995 - (Coleção Magistério: Formação e trabalho pedagógico).

VEIGA, I. P.A. (Org.). Projeto Político-Pedagógico: educação superior. Campinas, SP; Papirus, 1998.

VELOSO, C. Literatura comparada. São Paulo: Nova Cultural, 1988.

ZAKRZEVSKI, S. B. Por uma educação ambiental crítica e emancipatória In: REBEA. Revista Brasileira de Educação Ambiental. Brasília: REBEA, 2004. p. 79-86. 